\title{
Condicionantes para cultivo de soja tolerante ao déficit hídrico no Semiárido
}

\section{Nordestino}

\author{
Conditioners for cultivation soybean tolerant to the water deficit in the Northeast Semi-arid \\ Limitaciones para el cultivo de soja tolerante al déficit hídrico en la región Semiárida del Noreste
}

\author{
Jeandson Silva Viana \\ ORCID: https://orcid.org/0000-0002-8958-2873 \\ Universidade Federal do Agreste de Pernambuco, Brasil \\ E-mail: jeandsonsv@yahoo.com.br \\ Cleyton Tenório-Barros \\ ORCID: https://orcid.org/0000-0002-2459-1912 \\ Universidade Federal Rural de Pernambuco, Brasil \\ E-mail: cleytontenorio@hotmail.com \\ João Paulo Goes da Silva Borges \\ ORCID: https://orcid.org/0000-0003-2707-6489 \\ Universidade Federal do Agreste de Pernambuco, Brasil \\ E-mail: joaopaulobiologia4@gmail.com \\ Maria Beatrice Gueiros Silva \\ ORCID: https://orcid.org/0000-0001-8039-0173 \\ Universidade Federal do Agreste de Pernambuco, Brasil \\ E-mail: beatrice.gueiros@gmail.com \\ Edilma Pereira Gonçalves \\ ORCID: https://orcid.org/0000-0001-5150-7088 \\ Universidade Federal do Agreste de Pernambuco, Brasil \\ E-mail: edilmapg@hotmail.com \\ Mácio Farias de Moura \\ ORCID: https://orcid.org/0000-0002-3347-2368 \\ Universidade Federal do Agreste de Pernambuco, Brasil \\ E-mail: macio.farias@ufape.edu.br
}

\begin{abstract}
Resumo
A soja é uma cultura de grande expressividade mundial e o Brasil atualmente é o maior produtor e exportador dessa cultura, com potencial territorial para expansão do seu cultivo. Diante das previsões apontadas pelas principais instituições governamentais (mudanças climáticas, aumento populacional e a escassez dos recursos hídricos), garantir a segurança alimentar de uma população crescente exigirá estratégias e melhorias que visem o aumento da produtividade. Objetivou-se identificar atributos do meio e das plantas de soja que as tornem tolerantes ao déficit hídrico e que possibilitem o incremento da produção em ambientes semi-áridos do nordeste do Brasil. Tendo em vista que a maioria dos grandes países produtores de soja são compostos em sua maior parte de territórios áridos e semiáridos, e decorrente às atuais mudanças climáticas, existe uma forte tendência de que novas áreas possam estar se tornando áridas e semiáridas. As soluções para enfrentar o estresse decorrente do déficit hídrico imposta à soja em ambientes áridos e semiáridos precisam estar relacionados ao melhoramento fisiológico, morfológico e genético que auxiliem no enfrentamento desse estresse. Aumento das raízes, maior eficiência na fixação de nitrogênio, controle na condutância estomática e o uso eficiente da água por parte da planta são alguns dos desafios que a engenharia genética deverá responder para o desenvolvimento de uma variedade de soja tolerante ao déficit hídrico. Mais estudos que visem encontrar respostas capazes de solucionar o déficit hídrico na soja devem ser conduzidos.
\end{abstract}

Palavras-chave: Mudanças climáticas; Produção de sequeiro; Segurança alimentar.

\section{Abstract}

Soy is a crop of great expressiveness worldwide and Brazil is currently the largest producer and exporter of this crop, with territorial potential for expansion of its cultivation. In view of the forecasts made by the main governmental institutions (climate change, population increase, and the scarcity of water resources), ensuring food security for a growing population will require strategies and improvements aimed at increasing productivity. The objective was to identify attributes of the environment and soybean plants that make them tolerant to water deficit and enable increased production in semi-arid environments in northeastern Brazil. Given that most of the major soy producing countries are composed mostly of arid and semi-arid territories, and due to the current climate changes, there is a strong tendency that new areas may be becoming arid and semi-arid. The solutions to cope with the water deficit stress imposed on soybean in arid and semi-arid environments need to be related to physiological, morphological and genetic improvements to help cope with this stress. Root enlargement, increased efficiency in nitrogen fixation, control of 
stomatal conductance and the efficient use of water by the plant are some of the challenges that genetic engineering will have to address in order to develop a water deficit tolerant soybean variety. More studies that aim to find answers capable of solving the water deficit in soybean should be conducted.

Keywords: Climate change; Dryland production; Food security.

\section{Resumen}

La soja es un cultivo de gran expresividad mundial y Brasil es actualmente el mayor productor y exportador de este cultivo, con potencial territorial para la expansión de su cultivo. A la vista de las previsiones de las principales instituciones gubernamentales (cambio climático, aumento de la población y escasez de recursos hídricos), garantizar la seguridad alimentaria de una población creciente requerirá estrategias y mejoras destinadas a aumentar la productividad. El objetivo fue identificar los atributos del ambiente y de las plantas de soja que las hacen tolerantes al déficit hídrico y que permiten aumentar la producción en ambientes semiáridos del nordeste de Brasil. Teniendo en cuenta que la mayoría de los grandes países productores de soja están compuestos en su mayoría por territorios áridos y semiáridos, y debido a los cambios climáticos actuales, existe una fuerte tendencia a que nuevas zonas se conviertan en áridas y semiáridas. Las soluciones para afrontar el estrés por déficit hídrico impuesto a la soja en ambientes áridos y semiáridos deben estar relacionadas con mejoras fisiológicas, morfológicas y genéticas que ayuden a afrontar este estrés. El aumento de las raíces, la mayor eficiencia en la fijación del nitrógeno, el control de la conductancia estomática y el uso eficiente del agua por parte de la planta son algunos de los retos a los que debe responder la ingeniería genética para desarrollar una variedad de soja tolerante al déficit hídrico. Deberían realizarse más estudios para encontrar respuestas capaces de solucionar el déficit hídrico en la soja.

Palabras clave: Cambio climático; Producción en zonas áridas; Seguridad alimentaria.

\section{Introdução}

A soja [Glycine max (L.) Merrill] é uma das culturas mais importantes do mundo (Xu et al., 2018) e foi introduzida no Brasil como uma cultura de verão na produção de forragem em meados da década de 60. Com aumento do preço da soja na década de 70 essa cultura ganhou visibilidade por parte dos agricultores, que já produziam aproximadamente 500 mil toneladas/ano, conforme dados da Embrapa (2019).

A estimativa de área agricultável de soja para o ano-safra 2019/20 no Brasil, segundo boletim de dados de dezembro da Conab (2020), é de 38,175 Milhões de ha, com produtividade de aproximadamente 3.522kg/ha. Atualmente o Brasil é o maior exportador e produtor de soja do mundo, assumindo a liderança global e ultrapassando os Estados Unidos da América (EUA), com uma produção de 123 milhões de toneladas de soja no ano-safra 2019/20, chegando a 133 milhões de toneladas no anosafra 2020/21, segundo dados do Departamento de Agricultura norte-americano (Usda, 2020). Essa métrica de exportação não se restringe apenas ao maior exportador de soja do mundo. Dados da Comex Vis/MDIC (2020), aponta a soja como o primeiro entre todos Principais Produtos Exportados (PPE) no Brasil, alcançando um percentual de (jan/nov 2020), de 15\% de toda exportação do país, isso apenas, para soja triturada e 5,7\% para farelo e resíduos de extração de óleo de soja. Os valores acumulados da exportação de jan/nov 2020 no Brasil para a soja triturada correspondem a US\$ 28,5 Bilhões, e para exportação dos produtos derivados da soja US\$ 5,9 Bilhões (Comex VIS/MDIC, 2020).

A população mundial atualmente ultrapassa a marca de 7,6 bilhões de pessoas e previsões indicam que até 2050 esse número seja acrescido de 2,2 bilhões (Desa, 2017). Garantir a segurança alimentar de uma população crescente será um dos desafios futuros e exigirá um acréscimo de $70 \%$ na produção agrícola mundial (Fao, 2010) e o uso racional e eficiente da água deverá ser levado em consideração.

O planeta Terra é constituído $71 \%$ aproximadamente de água, mais apenas 3,5\% desta é doce e o restante compõe os oceanos (Leite et al., 2019). A Fao (2011) estima que aproximadamente 70\% da água doce disponível no mundo é usada na irrigação. Todavia, a água é um recurso finito e apenas $1 \%$ está disponível para consumo. Alterações climáticas naturais e principalmente antrópicas, concorrem para "não" ciclagem natural desse recurso, dificultando assim a percolação, aumentando o escoamento superficial e gerando uma diminuição nos estoques de água potável (Leite et al., 2019). As regiões semiáridas em toda parte do mundo apresentam características peculiares, como: altas temperaturas, baixos índices pluviométricos, umidade relativa do ar baixa, chuvas irregulares e/ou escassas, pouca variação na temperatura (amplitude térmica) e solos inférteis (Lemos 
\& Santiago, 2020). Desenvolver técnicas e variedades de culturas tolerante ao déficit hídrico será um desafio do século. Algumas culturas já apresentam bom desempenho na agricultura de sequeiro, como: algodão, milho, feijão, mandioca entre outra (Bittencourt et al., 2018; Lemos \& Santiago, 2020). Entretanto, cultura como a soja, que também depende de simbiose com bactérias nitrificadoras, ainda não tem desempenho de cultivo em sequeiro comprovado nas condições do semi-árido, tanto pelas altas temperaturas e baixas latitudes, como, principalmente, pelos déficit hídrico ocorrente no nordeste brasileiro.

Visando todo o quadro de mudança climáticas, aumento populacional acima dos limites de crescimentos agrícola mundiais, insegurança alimentar, redução da água potável e o possível potencial de áreas agricultáveis do Brasil e do mundo com enfoque na produção de soja em zonas áridas e semiáridas, objetivou-se identificar atributos do meio e das plantas de soja que as tornem tolerantes ao déficit hídrico e que possibilitem o incremento da produção em ambientes semi-áridos do nordeste do Brasil.

\section{Metodologia}

Essa pesquisa constituiu-se de um levantamento sistemático de revisão bibliográfica qualitativa (Pereira et al., 2018). Os artigos científicos aqui citados compõem a coletânea de dados de periódicos nacionais e internacionais, disponíveis nas seguintes bases de dados: Web of Science ${ }^{\mathrm{TM}}$ (https://www.webofknowledge.com), Scopus ${ }^{\circledR}$ (https://www.scopus.com), SciELO (https://scielo.org/en/), USDA (https://www.usda.gov), Google Scholar (https://www.scholar.google.com), EMBRAPA (https://www.embrapa.br) e CONAB (https://www.conab.gov.br). Termos relacionados a "soybean AND crop OR genetic improvement OR production OR tolerant to water deficit", traduções e termos correlatos foram associados e utilizados como palavras-chave nas buscas, conforme adaptações realizadas nos métodos de Oya et al. (2017). Em nossas buscas não houve restrições de ano e a última busca foi realizada em janeiro de 2020.

\section{Resultados e Discussão}

\section{Mecanismos: fisiológicos, morfológicos, metabólicos e climáticos em plantas de soja}

A água é um fator limitante para grande maioria das culturas agricultáveis do mundo e a planta durante seu ciclo de vida regular, sofre estresse por déficit hídrico (Benjamin \& Nielsen, 2006). E mecanismo de alteração fisiológicas que incluam sistemas de enraizamento mais profundos, fixação de nitrogênio, diminuição na condutância estomáticas e eficiência no uso da água têm sido visto como estratégias de tolerância ao déficit hídrico (Mutava et al., 2015), visto que fatores abióticos representam 50\% da redução na produção agrícola (Wang et al., 2003).

Todavia, ambientar culturas susceptíveis a limitação hídrica e sua aptidão na eficiência do uso da água será de extrema importância para desenvolver culturas resilientes ao clima, capaz de produzir alimento, mesmo submetidas ao estresse hídrico (Mutava et al., 2015). Sadok e Sinclair (2011) apontam três direcionamentos para mitigar o impacto negativo do déficit hídrico na produção agrícola: conservar a água do solo, acessar mais água e superar as sensibilidades impostas pelo déficit. Esforços que visem tais níveis futuros de produção requisitarão o uso de glebas já existentes ou novas, com provimentos hídricos escassos (Sinclair et al., 2010).

Modelos de simulação de safra mostra impactos mundiais negativos na produção agrícola decorrentes dos fatores climáticos, relatando tendências crescente na temperatura (Sivakumar et al., 2005), e análises temporais previsto para 2050 prever uma redução nos níveis pluviométricos de 20 a 25\% dos atuais para regiões áridas e semiáridas do mundo (Ragab \& Prudhomme, 2002).

O bom desenvolvimento das raízes, o melhoramento na absorção de água das camadas mais profundas, as altas taxas de fotossíntese, a condutância estomática e os ajustes de turgor celular é o que permite que as plantas se tornem resistentes em 
períodos de déficit hídricos, além de uma nutrição balanceada de todos os elementos essenciais, dão condições para que a planta se desenvolva sob condições limitantes.

Sob condições de estresse hídrico, a planta exibe uma demanda aumentada de potássio (K) para manter a fotossíntese e proteger os cloroplastos do dano oxidativo, sendo esse, o segundo nutriente mas usado pela soja, com o aumento do déficit hídrico (Souza et al., 2013). A presença de K na planta promove a manutenção do turgor das células-guarda, permitindo melhor abertura e fechamento da dinâmica dos poros estomáticos (Prado, 2008) e sua deficiência pode aumentar a produção de radicais livres, causa distúrbios no mecanismo de abertura e fechamento dos estômatos, reduzindo a fotossíntese e alavanca a sobra de eletros, que são desviados para produção de formas reativas de oxigênio (Catuchi et al., 2012).

O fósforo (P) na planta de soja é um dos principais nutrientes e está diretamente relacionado ao crescimento das raízes, possui grande importância no crescimento das plântulas no início do seu desenvolvimento, ajuda na fixação de nitrogênio e facilita a fotossíntese, devido ao aumento da condutância estomática em condições de restrição hídrica, melhorando, assim, a eficiência no uso da água, sendo, um grande aliado contra o estresse hídrico, estando ainda envolvido na resistência de algumas doenças e no auxilia no aumento da produtividade (Devi et al., 2012). Leite et al. (2019), em seu experimento com adubação fosfatada em três anos safra (2013/2014, 2014/2015 e 2015/2016) puderam observar o incremento na produção, mesmo a cultura submetida a déficit hídrico, o que mostra quão importante é uma boa adubação preparatória para a cultura da soja.

O cálcio (Ca) desempenha um papel importante na absorção de íons, no desenvolvimento radicular e na germinação de grãos de pólen (Vitti et al., 2006) por promover a manutenção do metabolismo celular sob condições de déficit hídrico e auxilia na recuperação da planta (Waraich et al., 2011).

Dessa forma, uma boa adubação provida de K, P e Ca em cultivares submetidos ao déficit hídrico, elevam os nutrientes da planta que podem ajudar na translocação de fotoassimilados no floema; manter as atividades fotossintéticas, e uma boa condutância estomática; ajuda a proteger os cloroplastos de danos oxidativos; melhora o desenvolvimento das raízes e plântulas em estágios iniciais; aumenta a capacidade de absorção de íons no desenvolvimento radicular e ajuda na recuperação da planta.

\subsection{Sistema radicular: morfologia, micro-organismos e fertilidade do solo}

A predisposição de uma cultura e sua capacidade de expandir suas raízes em maior profundidade no solo em busca de água, pode ser uma estratégia decisiva para adaptação de uma cultura ao déficit hídrico, podendo esse mecanismo, lograr maiores benefícios a produção agrícola no clima semiárido (Benjamin \& Nielsen, 2006). O acesso a água do solo em grandes profundidades exige alteração da arquitetura radicular e/ou atividade fisiológica das plantas, possibilitando assim a obtenção das águas de drenagem não disponível a uma planta convencional (Sadok \& Sinclair, 2011).

Estudos de sistemas radiculares em plantios agrícolas no decorrer dos últimos 40 anos vem demonstrando que o alongamento das raízes proporciona uma maior resiliência ao déficit hídrico e aumenta a tolerância a esse estresse em regiões de áridas e semiáridos em diversas culturas. Amendoim e feijão (Pandey et al., 1984), feijão musgo (Sponchiado et al., 1980), milho (Sinclair \& Muchow, 2001), soja (Sponchiado et al., 1980; Battisti et al., 2017), sorgo e trigo (Jordan et al., 1983).

Battisti et al. (2017) observaram que quando houve um melhoramento na qualidade do solo, o crescimento radicular da soja era beneficiado conseguindo melhores profundidades. Ponderar a respeito do ambiente físico (textura, estrutura, compactação e profundidade), químicos (toxicidades de $\mathrm{Al}$ e Na) e bióticos (nematoides e fungos) (Passioura, 1983), será vantajoso em situações em que a umidade do solo esteja disponível apenas em grandes profundidades, permissíveis a plantas que obtiverem maior desenvolvimento das raízes (Sadok \& Sinclair, 2011), apresentando assim uma resposta significativa ao estresse hídrico. Na década de 80, trabalho como de Cortez \& Sinclair (1986) já mostravam resultados positivos de tolerância a seca em soja, proporcionados por um maior enraizamento. 
Entre os micro-organismos que compõem o solo, as rizobactérias são as que apresentam um maior potencial benéfico, capaz de promover o crescimento das plantas (Ruzzi \& Aroca, 2015), e a elevada disponibilidade de fósforo solúveis no solo se relaciona diretamente com o metabolismo das rizobactérias promotoras de crescimento de plantas (RPCP), pelo aumento da absorção desse elemento (Araújo, 2008). Os micro-organismos do solo indiretamente aumentam eficiência do uso da água, radiação e sua captura (Mondani et al., 2019). Alguns RPCPs podem aumentar a superfície radicular enquanto outras podem entrar nas raízes e desenvolver populações endofíticas benéficas a planta hospedeira (Adesemoye \& Kloepper, 2009). Os RPCP também modulam os hormônios relacionados aos estresses hídrico e salino (Sharifi \& Ryu, 2018). Mondani et al. (2019) ao inocularem as RPCP na soja obtiveram como efeito aumento no crescimento, rendimento, aumento máximo de peso fresco e seco, maior comprimento da raízes e brotamentos do número de folhas, como também uma melhor eficiência no uso da água, quando comparados a tratamentos em que não foram inoculados.

Segundo Sharifi et al. (2010) o RPCP reduziu o estresse hídrico, produzindo polissacarídeos extracelulares, trealose-6fosfato e nutrientes solubilizantes. E Choudhary et al. (2011) afirmam que essa tolerância ao estresse do déficit hídrico pode ser aumentada através da redução dos níveis de etileno pela hidrólise do ácido 1-aminociclopropano-1 carboxílico.

A fixação de Nitrogênio $\left(\mathrm{N}_{2}\right)$ é um traço alvo de tolerância a seca (Sinclair et al., 2007). E no cultivo da soja a fixação de $\mathrm{N}_{2}$ é extremamente sensível ao estresse hídrico, sendo a taxa de fixação reduzida nos primeiros processos de secagem do solo (Purcell \& King, 1996), tornando-se sua nodulação e fixação comprometida pela temperatura do solo em cultivares de soja (Viana et al., 2013). A nutrição nitrogenada da soja é um dos principais processos e agrega produtividade e rentabilidade a cultura (Souza et al., 2013). Sinclair et al. (2010) comprovaram que cultivares que apresentaram maior fixação de $\mathrm{N}_{2}$, quando submetidos ao estresse hídrico, apresentaram um melhor resultado em todos os parâmetros testados para mitigar o déficit hídrico, incluindo fechamento estômatos, murchamento lento e aumento das raízes.

O déficit hídrico promove acúmulo de substâncias de $\mathrm{N}_{2}$ (Ureídeos) na parte aérea da planta da soja, causando uma redução na resposta de fixação, mas, a fertilização adequada do solo, possibilitando a absorção do íon de $\mathrm{Mn}^{2+}$ pelas plantas promove a quebra dessas substâncias facilitando a fixação do $\mathrm{N}_{2}$ sob condições de déficit hídrico (Souza et al., 2013). Estudos evidenciam que as altas concentrações de $\mathrm{N}_{2}$ na parte aérea, bem como a nitrificação dessa substância, pode ser solucionado, pela utilização de adubos nitrogenados de baixa solubilidade e inibidores de nitrificação (Chilundo et al., 2018).

Em solos ácidos, contendo alumínio tóxico $\left(\mathrm{Al}^{3+}\right)$ com baixa pluviosidade durante o ciclo da cultura podem limitar a expansão radicular, pela inibição da síntese de DNA e divisão celular, inibindo o crescimento das raízes e a captura de água em solos mais profundos (Souza et al., 2013). No Brasil a forma, mais utilizada para correção do alumínio tóxico é a cal (Soratto \& Crusciol, 2008), porém, outros materiais podem ser utilizados para essa correção: óxidos, hidróxidos, carbonatos e silicatos de cálcio e / ou magnésio (Ramos et al., 2006).

\subsection{Relações morfológicas, fisiológicas e climáticas da parte aérea}

Alcançar a segurança alimentar exigirá uma capacidade cognitiva de compreensão de todos os processos abióticos enfrentados pelas plantas, com o intuito de obter variedades de culturas que possam manter melhores rendimentos, mesmo submetidas ao estresse hídrico (Morison et al., 2008). O estresse hídrico severo, pode resultar em comprometimento da fotossíntese, distúrbios metabólicos e finalmente, morte da planta (Souza et al., 2013); já a perda moderada da água causada por um déficit em sua distribuição, tem como efeito a redução das trocas gasosas, fechamentos de estômatos, diminuição das condutâncias estomáticas, resistência a embolia do xilema, perda de turgor celular e expansão celular, inibindo o crescimento da planta (Sadok \& Sinclair, 2011). 
As modificações morfológicas na folha podem desempenhar uma importante estratégia da planta na tolerância ao déficit hídrico. Para a planta persistir a um período prolongado de seca, é importante que a planta adapte sua condutância estomáticas, visando uma menor perda de água na planta (Ku et al., 2013).

Sinclair et al. (2010) em seus experimentos comprovaram que através de uma diminuição precoce na condutância estomática foi possível preservar a água do solo, quando ele começou a secar obtendo benefícios sobre o estresse hídrico. Eles também observaram que genótipos de soja que fecharam seus estômatos no início do processo de secagem do solo, obtiverem rendimentos superiores a 79\% quando comparado a cultivares convencionais em três trimestres nos Estados Unidos, em região produtora de soja.

A fotossíntese é o processo responsável por toda assimilação de carbono da planta e para se obter uma produtividade satisfatória sob quaisquer condições climáticas, é necessário que exista uma eficiência mínima desse ciclo (Souza et al., 2013), sendo também um dos principais processos fisiológicos afetados em condições de déficit hídrico, podendo em estresses severos ser totalmente comprometido. Diante das condições climáticas atuais, estudos vêm tentando diagnosticar as implicações do estresse hídrico nos parâmetros fisiológicos da fotossíntese em diferentes genótipos de soja (Catuchi et al., 2012).

Catuchi et al. (2011; 2012) observaram nas cultivares "CD 202, CD 226RR, BR 16 e Embrapa 48", que a taxa fotossintética, a condutância estomática e a transpiração foram reduzidas por déficits hídricos. Catuchi et al. (2011) realizando experimento em vasos, utilizando reposição diárias de irrigação (100\% e 40\%) com base na variação diária dos pesos dos vasos, em duas cultivares a "CD 2002" convencional e a CD226RR transgênico, observaram que a medida em que o teor relativo de água e o potencial hídrico diminuem, a taxa fotossintética das folhas também diminui. Essa diminuição se deu pela limitação da entrada de $\mathrm{CO}_{2}$ pelos estômatos, restringindo as atividades fotoquímicas e bioquímicas da fotossíntese. Também observaram que a diminuição fotossintética na cultivar convencional não se deu por causas estomáticas, por outro lado plantas que foram submetidas ao déficit de irrigação $40 \%$, apresentaram uma maior capacidade de troca gasosa, reduziram a condutância estomática possibilitando uma maior assimilação de $\mathrm{CO}_{2}$, gerando economia de água para cada molécula de $\mathrm{CO}_{2}$, aumentando a eficiência de uso da água (EUA). Resultados semelhantes também foram encontrados por Catuchi et al. (2012) trabalhando em casa de vegetação com as cultivares BR-16, Embrapa 48, consideradas cultivares tolerante e suscetível ao estresse hídrico. Viana et al. (2013), em investigação dos experimentos conduzidos em estados do semiárido brasileiro, pode observar que devido aos avanços genéticos vários cultivares como: BRS Tracajá, BRS Sambaíba, 171 BCR1069X7RG, 174 BCR1069X7RG, M-SOY 8411, entre outros genótipos, apresentaram bom rendimento e resistência ao déficit hídrico, sendo esse fator um dos precursores para a expansão da soja no nordeste do Brasil.

Segundo Sadok e Sinclair (2011), a embolia do xilema pode mitigar o déficit hídrico e ser observado como uma estratégia de sobrevivência benéfica em culturas submetidas a estresses severos. Através de cavitação e embolia, a translocação de água é impedida dentro do xilema, minimizando o transporte de água para as folhas, resultando em menor transpiração e fotossíntese.

A ocorrência do déficit hídrico na soja acentua problemas de floração, formação e retenção de vagens, diminuindo assim o seu rendimento (Viana et al., 2013). He et al. (2017) sugerem que o uso regrado da água antes da floração beneficia o rendimento da cultura e mitiga a tolerância da soja à seca. Fato semelhante também foi observado por Vadez et al. (2013), que observaram que sob seca terminal as culturas que receberam água antes do florescimento foram beneficiadas. He et al. (2017) também relatam que a floração precoce pode reduzir o consumo de água e as altas temperaturas podem levar a soja a florescerem precocemente.

Sob estresse hídrico, manter a turgidez da célula é um fator de alta importância (Manavalan et al., 2009). O ajuste osmótico é o mecanismo que mantém essa turgidez. Resposta a desidratação lenta é dada por elementos osmorreguladores que mantém os ajustes metabólicos de controle osmótico (Souza et al., 2013). Nepomuceno et al. (2001) destaca que plantas sob 
déficit hídrico desenvolve mecanismos de ativação de genes que promovem tolerância a desidratação celular, mantendo o turgor da célula próximo a níveis satisfatório para a planta. O ajustamento osmótico possibilita a manutenção do turgor nas regiões meristemáticas, levando a restauração da homeostase celular, possibilitando a sobrevivência das plantas ao estresse hídrico (Souza et al., 2013). O ajustamento osmótico é um diminuidor do potencial osmótico em resposta ao déficit hídrico ou à salinidade (Turner, 1986), permitindo a manutenção de uma turgescência positiva em potenciais hídricos relativamente mais baixos (Souza et al., 2013). E esse processo se dá pelo acúmulo de compostos orgânicos osmoticamente ativos, como os carboidratos e proteínas solúveis, aminoácidos, prolina, compostos quaternários de amônia como a betaína e a glicina-betaína, entre outras substâncias, que têm função osmorreguladora e protetora (Jongdee et al., 2002; Moura et al., 2016). Jongdee et al. (2002) apontam a estratégia de ajuste osmótico como critério de seleção para melhorar a tolerância à seca no arroz de sequeiro.

\subsection{Engenharia genética e transgênica}

A tecnologia da engenharia genética oportuniza soluções viáveis para superar os efeitos negativos do estresse em plantas, facilitando o desenvolvimento de soluções antes impossível com o melhoramento convencional (Kim et al., 2018). Com os crescentes avanços biotecnológicos, recursos de germoplasma e ferramentas genômicas disponíveis à transgenia torna-se uma alternativa palpável para o melhoramento genético e o grande desafio a ser enfrentado é identificar os genes responsáveis pela tolerância ao déficit hídrico (Ku et al., 2013).

A diversidade de cultivares genéticos em soja já é globalmente conhecido, e pesquisas genéticas e reprodutivas adequadas, poderá levar a cultura da soja a se adaptar e adquirir resistência à uma gama de condições ambientais (Viana et al., 2013). Considerar grupos genótipos que apresentem características morfológicas e fisiológicas, que se adaptem para enfrentar o estresse hídrico, devem ser levados em consideração durante o processo de melhoramento genético para obtenção de novas variedades de soja, que exibam tolerância durável à seca (Prado et al., 2001).

$\mathrm{Ku}$ et al. (2013) afirmam que desenvolver um cultivar de soja convencional exige um longo processo sucessório de cruzamentos e reproduções seletivas. Durante seis gerações na China foram realizados experimentos de cruzamento das cultivares Xiàn White Soybean (uma antiga cultivar de alta tolerância à seca, mas com menor rendimento) e Jindou 2 (tolerante à seca, alto rendimento e maturação precoce). A longa sucessão de cruzamentos culminou na cultivar Jindou 21, que apresentou maior rendimento e maior tolerância à seca, sendo hoje uma das variedades mais cultivadas no semiárido da China.

O ácido abscísico (ABA) é um fitohormônio regulador fisiológico das plantas (Sadok \& Sinclair, 2011; Xu et al., 2018) e é sintetizado por vários tipos de células, incluindo as da raiz, parênquima e mesófilo (Wilkinson \& Davies, 2010) e são cruciais na integração de sinalização e controle de respostas para vários estresses, incluindo o déficit hídrico (Verma et al., 2016). O ABA aumenta a tolerância da planta à seca, promovendo fechamento de estômatos e minimizando a transpiração (Dodd et al., 2010), e pode aumentar o alongamento das raízes primárias (Mondani et al., 2019).

No estudo de Xu et al. (2018) foi descoberto que os níveis de expressão de três genes, zeaxantina epoxidase (ZEP), 9cis-epoxicarotenoide dioxigenase (NCED) e $A B A 2$, são responsáveis pela síntese de $\mathrm{ABA}$. Eles observaram que dentre os vários genes envolvidos na síntese de ABA, a identificação dos três genes indicou que, na soja, eles podem desempenhar papéis mais importantes do que outros, destacando esses genes como promissores para uso alvo da engenharia genética ou melhoramento molecular para enfrentar a tolerância à seca na soja.

\section{Conclusão}

Cultivares que apresente um maior enraizamento, aumento da fixação de nitrogênio em solo secos, controle da condutância estomática reduzindo a transpiração da planta, que conseguem manter a turgescência da célula através do ajuste osmótico, florescimento precoce e o uso eficiente de água pela planta, são características que devem aparecer em um cultivar 
para se tolerar o estresse hídrico. Estudos devem ser direcionados almejando entender a embolia do xilema. O melhoramento das condições de nutrição do solo e a inoculação de rizobactérias podem ter um papel importante no crescimento radicular e na absorção da água em grandes profundidades do solo. O desenvolvimento de novas variedades de soja que apresentem características tolerantes ao déficit hídrico é, atualmente, o maior desafio imposto à engenharia genética e tecnologias que permitam solucionar essa problemática e possibilitará o incremento da soja em ambientes áridos e semiáridos do Brasil e do mundo. Diante do apresentado, levar em consideração as variedades de soja que já apresentem características tolerantes ao déficit hídrico e o manejo da cultura, que poderão ser a chave para se chegar a uma cultivar que tenha uma maior resistência ao estresse hídrico. Em suma, estudos futuros deverão focar em encontrar genes, hormônios sintéticos e variedades de soja que sejam tolerantes ao déficit hídrico ou empregado em cruzamentos com cultivares já indicadas para baixas latitudes, onde ocorre o maior bioma brasileiro relacionado ao semi-árido, a caatinga.

\section{Agradecimentos}

Os autores agradecem ao apoio financeiro da Coordenação de Aperfeiçoamento de Pessoal de Nível Superior - Brasil (CAPES) e ao Programa de Pós-Graduação em Produção Agrícola da Universidade Federal Rural de Pernambuco, pelo apoio dado à disciplina Sistemas Locais de Produção Agrícola, que resultou no trabalho de revisão.

\section{Referências}

Adesemoye, A. O. \& Kloepper, J. W. (2009). Plant-microbes interactions in enhanced fertilizer use efficiency. Applied Microbiology and Biotechnology, 85, 112. DOI $10.1007 / \mathrm{s} 00253-009-2196-0$

Araujo, F. F. (2008). Inoculação de sementes com Bacillus subtilis, formulado com farinha de ostras e desenvolvimento de milho, soja e algodão. Ciência e Agrotecnologia, 32(2), 456-462. 10.1590/S1413-70542008000200017.

Battisti, R., Sentelhas, P. C., Boote K. J., Câmara, G. M. S., Farias, J. R. B. \& Basso, C. J. (2017). Assessment of soybean yield with altered water-related genetic improvement traits under climate change in Southern Brazil. European Journal of Agronomy, 83, 1-14. https://doi.org/10.1016/j.eja.2016.11.004

Benjamin, J. G. \& Nielsen, D. C. (2006). Water deficit effects on root distribution of soybean, field pea and chickpea. Field Crops Research, 97(2/3), 248-253. 10.1016/J.FCR.2005.10.005

Bittencourt, F., Mantovani, E. C., Sediyama, G. C. \& Santos, N. T. (2018). Determinação de funções de produtividade de algodão e soja em cultivo sequeiro no extremo oeste da Bahia. Revista Agrogeoambiental, 10(1), 67-81. http://dx.doi.org/10.18406/2316-1817v10n120181089

Catuchi, T. A., Vítolo, H. F., Bertolli, S. C. \& Souza, G. M. (2011). Tolerance to water deficiency between two soybean cultivars: transgenic versus conventional. Ciência Rural, 31(3), 373-378. https://doi.org/10.1590/S0103-84782011000300002

Catuchi, T. A., Guidorizzi, F. V. C., Guidorizi, K. A., Barbosa, A. M. \& Souza, G. M. (2012). Respostas fisiológicas de cultivares de soja à adubação potássica sob diferentes regimes hídricos. Pesquisa Agropecuária Brasileira, 47(4), 519-527. https://doi.org/10.1590/S0100-204X2012000400007.

Choudhary, D. K., Sharma, K. P. \& Gaur, R. K. (2011). Biotechnological perspectives of microbes in agro-ecosystems. Biotechnol Lett, 33, 1905-1910. 10.1007/s10529-011-0662-0

Chilundo, M., Joel, A. Wesström, I., Brito, R. \& Messing, I. (2018). Influence of irrigation and fertilisation management on the seasonal distribution of water and nitrogen in a semi-arid loamy sandy soil. Agricultural Water Management, 199, 120-137. https://doi.org/10.1016/j.agwat.2017.12.020

Conab. (2020). Safra Brasileira de Grãos. Website da Companhia Nacional de Abastecimento - CONAB. https://www.conab.gov.br/info-agro/safras/graos

Cortes, P. M. \& Sinclair, T. R. (1986). Water Relations of Field-Grown Soybean under Drought. Crop Science, 26(5), 993-998. https://doi.org/10.2135/cropsci1986.0011183X002600050031x

Desa (2017) - United Nations, Department of Economic and Social Affairs, Population Division. World Population Prospects: The 2017 Revision. Key Findings and Advance Tables. Working Paper No. ESA/P/WP/248.

Devi, K. N., Singh, L. N. K., Devi, T. S., Devi, H. N.; Singh, T. B.; Singh, K. N. \& Singh, W. N. (2012). Response of Soybean [Glycine max (L.) Merrill] to Sources and Levels of Phosphorus. Journal of Agricultural Science, 4(6), 44-53. 10.5539/jas.v4n6p44

Dodd, I. C., Zinovkina N. Y., Safronova, V. I. \& Belimov, A. A. (2010). Rhizobacterial mediation of plant hormone status. Annal of Applied Biology, 157, 361379. 10.1111/j.1744-7348.2010.00439.x

Embrapa. (2019). História da Soja. Website da Empresa Brasileira de Pesquisa Agropecuária - EMBRAPA. https://bit.ly/2I8DOkt 
Fao. (2019). 'Climatesmart' agriculture, policies, practices and finances for food security, adaptation andmitigation. Website da Organização para a Alimentação e Agriculturahttps - FAO. //bit.ly/2X4AETh.

Fao. (2011). The state of the world's land and water resources for food and agriculture (SOLAW) - Managing systems at risk. FAO, Rome and Earthscan.

He, J., Du, Y., Wang, T., Turner, N. C., Yang, R., Xi, Y. J. Y., Zhang, C., Cui, T. \& Fang, X. Li, F. (2017). Conserved water use improves the yield performance of soybean (Glycine max (L.) Merr.) under drough. Agricultural Water Management, 179, 236-245. https://doi.org/10.1016/j.agwat.2016.07.008

Jongdee, B., Fukai, S. \& Cooper, M. (2002). Leaf water potential and osmotic adjustment as physiological traits to improve drought tolerance in rice. Field Crops Research, 76, 153-163. https://doi.org/10.1016/S0378-4290(02)00036-9

Jordan, W. R., Dugas, W. A. \& Shouse, P. J. (1983). Strategies for crop improvement for drought prone regions. Agricultural Water Management, 7, 281-299. https://doi.org/10.1016/0378-3774(83)90090-2

Lemos, J. \& Santiago, D. (2020). Instabilidade Temporal na Produção Agrícola Familiar de Sequeiro no Semiárido do Nordeste Brasileiro. Desenvolvimento Em Questão, 18(50), 186-200. https://doi.org/10.21527/2237-6453.2020.50.186-200

Kim, H., Cho, H. S., Pak, J. H., Kwon, T., Lee, J., Kim, D., Lee, D. H., Kim, C. \& Chung, Y. (2018). Confirmation of Drought Tolerance of Ectopically Expressed AtABF3 Gene in Soybean. Molecular and Cellular Biology, 41, 413-422. 10.14348/molcells.2018.2254

Ku, B. Y., Au-Yeung, W., Yung, Y., Li, M., Wen, C., Liu, X. \& Lam, H. (2013). Drought stress and tolerance in soybean. In: Board, J.E. A Comprehensive Survey of International Soybean Research - Genetics, Physiology, Agronomy and Nitrogen Relationships. 10, 209-237. 10.5772/52945

Leite, M. A., Dias, F. A., Hernandes, F. B. T. \& Oliveira J. N. (2019). Usos múltiplos da água. In: Dornfeld, C. B., Talamoni, A.C.B., Queiroz, T.V. O Jogo digital na sala de aula - Água, Ação E Reflexão: elaboração de jogo digital para a Educação Básica. 4, 44-57.

Manavalan, L. P., Guttikonda, S. K., Tran, L. P. \& Nguyen H. T. (2009). Physiological and molecular approaches to improve drought resistance in soybean. Plant and Cell Physiology, 50(7), 1260-1276. https://doi.org/10.1093/pcp/pcp082

MDIC. (2020). Ministério do Desenvolvimento, Indústria e Comércio Exterior - Comex Vis/MDIC. Website do MDIC. http://comexstat.mdic.gov.br/pt/comexvis.

Mondani, F., Khani, K., Honarmand, S. J. \& Saeidi, M. (2019). Evaluating effects of plant growth-promoting rhizobacteria on the radiation use efficiency and yield of soybean (Glycine max) under water deficit stress condition. Agricultural Water Management, 213, 707-713. https://doi.org/10.1016/j.agwat.2018.11.004

Morison, J. I. L., Baker, N. R., Mullineaux, P. M. \& Davies, W. J. (2008). Improving water use in crop production. Philosophical Transactions of the Royal Society Biological Sciences, 363, 639-658. 10.1098/rstb.2007.2175

Moura, A. R., Nogueira, R. J. M. C., Silva, J. A. A. \& Lima, T. V. (2016). Water relations and organic solutes in young plants of Jatropha curcas L. under diferente water regimes. Ciência Florestal, 26(2), 345-354.

Mutava, R. N., Prince, S. J. K., Syed, N. H., Song, L., Valliyodan, B., Chen, W. \& Nguyen, H. T. (2015). Understanding abiotic stress tolerance mechanisms in soybean: A comparative evaluation of soybean response to drought and flooding stress. Plant Physiology and Biochemistry, 86, 109-120. https://doi.org/10.1016/j.plaphy.2014.11.0104

NEPOMUCENO, A. L. et al. Tolerância à seca em plantas. Biotecnologia Ciência e Desenvolvimento, 23, 12-18, 2001.

Oya, C., Schaefer, F., Skalidou, D., McCosker, C., \& Langer, L. (2017). Effects of certification schemes for agricultural production on socio-economic outcomes in low-and middle-income countries: a systematic review. Campbell Systematic Reviews, 13(1), 1-346. 10.4073/csr.2017.3.

Pandey, R. K., Herrera, W. A. T. \& Pendleton, J. W. (1984). Drought response of grain legumes under irrigation gradient. III. Plant growth. Agronomy Journal, 76, 557-560. https://doi.org/10.2134/agronj1984.00021962007600040011x

Passioura, J. B. (1983). Roots and drought resistance. Agricultural Water Management, 7, 265-280. https://doi.org/10.1016/0378-3774(83)90089-6

Pereira, A. S., Shitsuka, D. M., Parreira, F. J., \& Shitsuka, R. (2018). Metodologia da pesquisa científica. UFSM

Prado, R. M. (2018). Nutrição de plantas. UNESP.

Prado, E. E., Hiromoto, D. M., Godinho, V. P. C., Utumi, M. M. \& Ramalho, A. R. (2001). Adaptability and stability of soybean cultivars in five planting seasons in Rondônia cerrado. Pesquisa Agropecuária Brasileira, 36(4), 625-635. https://doi.org/10.1590/S0100-204X2001000400005

Purcell, L. C. \& King, C. A. (1996). Drought and nitrogen source effects on nitrogen nutrition, seed growth, and yield in soybean. Journal of Plant Nutrition, 19, 969-993. https://doi.org/10.1080/01904169609365173

Ragab, R. \& Prudhomme, C. (2002). Climate Change and Water Resources Management in Arid and Semi-arid Regions: Prospective and Challenges for the 21st Century. Biosystems Engineering, 81(1), 3-34. https://doi.org/10.1006/bioe.2001.0013

Ramos, L. A., Nolla, A., Korndörfer, G. H., Pereira, H. S. \& Camargo, M. S. (2006). Reactivity of soil acidity correctives and conditioners in lysimeters. Revista Brasileira de Ciência do Solo, 30, 849-857. https://doi.org/10.1590/S0100-06832006000500011

Ruzzi, M. \& Aroca, R. (2015). Plant growth-promoting rhizobacteria act as biostimulants in horticulture. Scientia Horticulturae, 196, 124-134. https://doi.org/10.1016/j.scienta.2015.08.042

Sadok, W. \& Sinclair, T. R. (2011). Crops Yield Increase Under Water-Limited Conditions: Review of Recent Physiological Advances for Soybean Genetic Improvement. Advances in Agronomy, 113, 325-349. https://doi.org/10.1016/B978-0-12-386473-4.00007-5 
Rouhallah, S., Masoud, A., Abbas, S. \& Khalil, T. (2010). Pyoverdine production in Pseudomonas fluorescens UTPF5 and its association with suppression of common bean damping off caused by Rhizoctonia solani (Kuhn). Journal of Plant Protection Research, 50, 72-78.

Sharifi, R. \& Ryu, C. M. (2018). Revisiting bacterial volatile-mediated plant growth promotion: lessons from the past and objectives for the future. Annals of Botany, 122(3), 349-358. 10.1093/aob/mcy108

Sinclair, T. R. \& Muchow, R. C. (2001). System analysis of plant traits to increase grain yield on limited water supplies. Agronomy Journal, 93(2), 263-270. https://doi.org/10.2134/agronj2001.932263x

Sinclair, T. R., Purcell, L. C., King, C. A., Sneller, C. H., Chen, P. \& Vadez, V. (2017). Drought tolerance and yield increase of soybean resulting from improved symbiotic N2 fixation. Field Crops Research, 101, 68-71. https://doi.org/10.1016/j.fcr.2006.09.010

Sinclair, T. R. Messina, C. D. Beatty, A. \& Samples, M. (2010). Assessment across the United States of the benefits of altered soybean drought traits. Agronomy Journal, 102(2), 475-482. https://doi.org/10.2134/agronj2009.0195

Sivakumar, M. V. K., Das, H. P. \& Brunini, O. (2005). Impacts of Present and Future Climate Variability and Change on Agriculture and Forestry in the Arid and Semi-Arid Tropics. Climatic Change, 70(1/2), 31-72. https://doi.org/10.1007/s10584-005-5937-9

Soratto, R. P. \& Crusciol, C. A. C. (2008). Nutrition and grain yield of black oat as affected by surface application of lime and phosphogypsum at the establishment of no-tillage system. Revista Brasileira de Ciência do Solo, 32, 715-725. https://doi.org/10.1590/S0100-06832008000200026.

Souza, G. M., Catuchi, T. A., Bertolli, S. C. \& Soratto, R. P. (2013). Soybean under Water Deficit: Physiological and Yield Responses. In: Board, J. E. A Comprehensive Survey of International Soybean Research - Genetics, Physiology, Agronomy and Nitrogen Relationships. 13, 273-298. 10.5772/54269

Sponchiado, B. N., White, J. W., Castillo, J. A. \& Jones, P. G. (1980). Root growth of four common bean cultivars in relation to drought tolerance in environments with contrasting soil types. Experimental Agriculture, 25(2), 249-257. https://doi.org/10.1017/S0014479700016756

Turner, N. C. (1986). Adaptation to water deficits: a changing perspective. Australian Journal Plant Physiology, 13, 175-190. https://doi.org/10.1071/PP9860175

Usda. (2020). Foreign Agricultural Service. Website do United States Department of Agriculture. https://bit.ly/2I9JQS1.

Vadez, V., Kholová, J., Yadav, R. S. \& Hash, C. T. (2013). Small temporal differences in water uptake among varieties of pearl millet (Pennisetum glaucum (L.) R. Br.) are critical for grain yield under terminal drought. Plant Soil, 371, 447-462. https://doi.org/10.1007/s11104-013-1706-0

Verma, V., Ravindran, P. \& Kumar, P. P. (2016). Plant hormone-mediated regulation of stress responses. BMC Plant Biology, 16(86), 1-10. https://doi.org/10.1186/s12870-016$0771-\mathrm{y}$

Viana, J. S., Gonçalves, E. P., Silva, A. C. \& Matos, V. P. (2013). Climatic conditions and production of soybean in northeastern Brazil. In: Board, J. E. A Comprehensive Survey of International Soybean Research - Genetics, Physiology, Agronomy and Nitrogen Relationships. 18, 377-392. 10.5772/52184

Vitti, G. C.; Lima, E. \& Cicarone, F. (2006). Nutrição mineral de plantas. Sociedade Brasileira de Ciência do Solo.

Wang, W. X., Vinocur, B. \& Altman, A. (2003). Plant responses to drought, salinity and extreme temperatures: towards genetic engineering for stress tolerance. Planta, 218(1), 1-14. https://doi.org/10.1007/s00425-003-1105-5

Waraich, E. A., Ahmad, R. \& Ashraf, M. Y. (2011). Role of mineral nutrition in alleviation of drought stress in plants. Australian Journal of Crop Science, 5(6), 764-778.

Wilkinson, S. \& Davies, W. J. (2010). Drought, ozone, ABA and ethylene: new insights from cell to plant to community. Plant, Cell \& Environment, 33(4), 510-525. 10.1111/j.1365-3040.2009.02052.x

Xu, C., Xia, C., Xia, Z., Zhou, X., Huang, J., Huang, Z., Liu, Y., Jiang, Y., Casteel, S. \& Zhang, C. (2018). Physiological and transcriptomic responses of reproductive stage soybean to drought stress. Plant Cell Reports, 37, 1611-1624. 10.1007/s00299-018-2332-3 